\title{
On the Design Principles and the Standards of Evaluation of EST Teaching Materials*
}

\author{
CHANG Yan \\ Qingdao University of Science and Technology, Qingdao, China
}

\begin{abstract}
In the whole teaching system for English majors, English for Science and Technology (EST) as a subject, plays an important role of helping English majors to broaden their knowledge and horizon, to master the methods and thinking mode of scientific research, and to improve their comprehensive ability on the basis of strengthen their English language communicative ability. Of all the components, textbooks are the carrier as well as the fundamental guarantee of success of EST teaching. With the detailed analysis of status of EST textbooks for English majors, including types and some existent problems, and with the probe into teaching objectives and teaching content of EST for English majors, this paper tends to propose some design principles and standards of evaluation for EST textbooks for EST researchers, in hope of improving the quality of EST textbooks for English majors so as to realize the all-sided improvements of EST textbooks, students, teachers, and the discipline itself.

Keywords: EST textbook for English majors, design principles, standards of evaluation
\end{abstract}

\section{Introduction}

In traditional language teaching of English majors, language skills training counts a lot. With the accelerating development of times, science, and the technology, the requirements for talents are much more demanding, which raises a higher standard for higher education. Hence, apart from basic language ability cultivation, such as competence of society, culture, literature, religion, politics, commerce, and so on, students' knowledge about science and technology becomes an essential and important aspect of language learning in today's modern social life.

Just like any other subject, in the whole and comprehensive education system, there are many elements which contribute to the teaching level and the quality of education, such as the model of instruction, the manipulation of the teaching methodology, the operation of the teaching program, the management of educational organization, the utilization of the teaching facilities, the design, the use, and evaluation of the teaching materials, and so on.

The teaching textbooks of EST are one of the most essential carriers of EST teaching activity, playing an important role in the whole process of the teaching program. They are not only the major source of EST language

\footnotetext{
* Acknowledgements: This paper is the achievement of a project sponsored by the Research of Education Science in Shandong Province in 2015 (No. 15SB009) (本文系山东省教育科学研究 2015 年度立项课题的研究成果, 项目编号 15SB009).

CHANG Yan, lecturer, master, School of Foreign Language Studies, Qingdao University of Science and Technology.
} 
input, but also the manifestation of the syllabus, instructional objectives, aims, content of EST, affecting the adjustment of the models of the instruction. EST textbooks are the elementary component, as well as a powerful guarantee of the successful EST teaching.

How to design, choose, utilize, and evaluate the EST teaching materials, especially textbooks, is one of the urgent problems in EST teaching. The author of this paper concentrates on the designing and the evaluation of EST textbooks for English majors.

\section{General Review of EST Teaching for English Majors}

\section{Types of Current EST Textbooks for English Majors}

According to the research of Hutchinson and Waters, there are basically three types of EST textbooks for English Majors:

The first type is the textbooks for the general science and technology, the source of which comes from various fields and domains, offering the target learners and readers general knowledge of all fields.

The second type focuses on the specific category of language training, such as the translation, the composition, the grammar, or the reading comprehension of EST article or passages, while the first two types usually strive to include all.

The third type is the textbooks of specific stages and domains, targeting learners of specific majors and professions, belonging to English for Special Purposes (ESP).

Due to the lack of background knowledge of certain fields and professions, EST textbooks for English majors are of mainly the first two types.

\section{Some Problems in Current EST Textbooks}

Presently, there are some problems and flaws existent in current EST textbooks.

(1) English language training cannot be organically combined with the learning of science and technology.

(2) There is lack of authenticity, which means the scarcity of real and actual contexts and authentic language sources. Hence, what the learners have gained cannot meet the requirement in their future study and career.

(3) The degree of difficulty has not been appropriately controlled, some textbooks are somehow casually compiled and some original textbooks introduced from English-speaking countries are beyond the ability of the students.

(4) The forms are quite simple and monotonous, with the printed version in paper as the main form, restricted within the in-class teaching activity, so multimedia textbooks are quite worthwhile developing.

\section{The Location and the Position of EST Teaching in the Whole English Language Teaching System for} English Majors

In order to design a good EST textbook and to make a scientific and objective evaluation of an EST textbook for English majors, it is quite necessary to figure out the position of this course in the whole teaching system for English majors.

The course of EST for English majors is an bridging course between GE (General English) and ESP (English for Special Purposes), aiming to cultivate inter-disciplinary and practical talents, helping English majors to develop from basic language skills learning to the learning of English for special purposes. 
With its distinctive features of scientific and technological vocabulary, unique syntactic structures, grammatical constructions, and professional expressive habits, EST learning is a progressive complement of and development from common English learning, and also an effective approach for English major student to broaden their horizon, to have an access to the leading-edge technologies and explorations.

\section{Teaching Contents and Objectives of EST for English Majors}

The course of EST for English majors aims to develop their comprehensive linguistic ability, especially their language command on the aspect of science and technology, on the base of improving their basic language skill, saying, listening, speaking, reading, writing, and translating, so as to lay a strong linguistic and intellectual foundation for science-and-technology-related career in the near future after their graduation.

Hence the content of EST teaching includes not only the language aspect, like scientific vocabulary, terms, and expression, scientific syntactic regulations and habits, scientific and technological texts comprehension and composition, but also general description, illustration, and explanation of simple and elementary scientific phenomenon in appropriate English language as well, broadening English majors intellective horizon and enhancing their communicative ability regarding science and technology.

\section{The Design Principles of EST Textbooks for English Majors}

Taking the problems existing in current EST textbooks for English Majors, the position of this subject in the whole educational system, the relationship between EST and other subjects, and the teaching objectives and contents into consideration, the author of this tentatively proposes some design principles for EST textbook compliers:

\section{Authenticity}

The source of the material in EST textbooks should rely on the original material in the target language itself, since the subject is, after all, of a kind of language study, although the language study component should be considered as being on the equal footing with the study of science and technology. Authentic language context can bring the EST learners into a true-like linguistic situation, helping them grasp the linguistic features of EST, so as to improve their communicative ability in English in the field of science and technology. Authentic EST textbooks can play an important role in realizing EST's function to bridge the scientific and technological study and language competence development.

\section{Appropriate Degree of Difficulty}

EST textbooks for English majors should fully consider the students' English language ability, their cognitive ability of science and technology and common learning pattern. Overestimation and underestimation of their potentials may hurt their interest and their passion and their self-confidence. Only EST textbooks with proper degree of difficulty can be helpful and practical.

\section{Compatibility}

As a kind of textbooks, EST textbooks are supposed to comply with the theoretical foundation, such as language teaching theory, language learning theory, linguistic theory, cognitive theory, interdisciplinary theory, and so on. What is more, the EST textbooks designers should strive to make the textbooks compatible with the compilation notion, design tendency, the thinking method, the objectives of EST course, and the syllabus of this 
course, on the basis of the extensive exploration of the current EST textbooks and the intensive analysis of each textbook's advantages and disadvantages.

\section{Diversity}

A large number of language sources are needed for EST textbook designing, which means not only the types of the language of EST, the fields of science and technology, but also the presentation forms, especially in this multimedia world. Compared with other subjects, the vocabulary and the expressions of EST are somewhat dull and difficult, and the content with background scientific and technological ability is hard for English majors. Thus diversified forms and contents, as well as various kinds of question types in the exercises, can be very effective to help the English majors to broaden their horizon, to build up a more scientific and systematic knowledge construction and to facilitate their life-long learning commitment of science and technology.

\section{The Standards of Evaluation of EST Textbooks for English Majors}

The following are some standards of evaluation of EST textbooks for English majors:

(1) A good EST textbook is absolutely a helpful device for the teachers' career development.

As an important component of higher education, the personal improvement of teachers for English majors is also a deserving issue. Usually, the periods of their career development are long; some teachers are still not competent to fulfill their EST teaching task. With an excellent EST textbook, it is much easier for the teachers to grasp the emphasis and difficult points in the teaching content, to manipulate the teaching process, so as to improve their teaching competence and to shorten their career development period. Moreover, they may choose teaching materials more creatively and flexibly.

(2) A good EST textbook for English majors should adapt to the development of the subject.

In today's modern world, science and technology develop in such an unbelieving speed, which in turn has been changing people's living and thinking method. As a direct manifestation of the social life, EST has been altering all the time. Therefore, timeliness becomes an important criterion for a good EST textbook, which can deliver a full text access to the world's highest quality technical literature in science and technology. With the detailed description and explanation of the phenomenon and the analysis of the complicated scientific problems, the students' attitude towards science and the meticulous thinking method can be cultivated.

(3) A good EST textbook for English majors is surely student-centered.

EST textbooks compiler and designer should abide by the notion of "student-centered" or "learning oriented", make an in-depth analysis of the learning process and requirements of English majors for EST learning, and stimulate their interest in learning the knowledge of science and technology as their life-long commitment.

\section{Conclusion}

Accompanied with the development of the society and the academic exploration of EST as a special subject, which acts the role of a bridge course between GE and ESP for language learners, the further teaching reform of EST requires high quality EST textbooks, which is an crucial component as well as a powerful guarantee of successful teaching of EST. After a detailed review of the significance, the types and the existent problems of EST textbooks, and the location and the position of EST teaching in the whole language teaching 
system for English majors, this paper tends to propose some design principles and standards of evaluation for EST textbooks for EST researchers.

\section{References}

Dudley Evans, T., \& St John, M. J. (1998). Development in English for specific purposes. Cambridge: Cambridge University Press. Harmer, J. (1983). The practice of English language teaching. London: Longman.

Hedge, T. (2002). Teaching and learning in the language classroom. Oxford: Oxford University Press.

Hutchinson, T., \& Waters, A. (1987). English for specific purposes: A learning-centered approach. Cambridge: Cambridge University Press.

Larsen-Freeman, D., \& Long, M. H. (2000). An introduction to second language acquisition research. Beijing: Foreign Language Teaching and Research Press.

Pinker, S. (1994). The language instinct. New York: William Morrow and Company, Inc..

Wesche, M. B., \& Skehan, P. (2002). Communicative, task-based and content-based language learning. In The Oxford handbook of applied linguistiecs (pp. 54-69). Oxford: Oxford University Press.

Widdowson, H. G. (1990). Aspects of language teaching. Shanghai: Shanghai Foreign Language Education Press.

Williams, M., \& Burden, R. L. (2000). Psychology for language teachers. Beijing: Foreign Language Teaching and Research Press. 